\title{
O ATLÂNTICO NEGRO: NARRATIVAS ACADÊMICAS E QUESTÕES PARA O ENSINO DE HISTÓRIA DAS AMÉRICAS
}

\section{LARISSA MOREIRA VIANA*}

\begin{abstract}
Resumo: $\mathrm{O}$ artigo aborda alguns saberes acadêmicos de História das Américas para ressaltar em que medida se inscrevem no processo de formação de docentes comprometidos com o enfrentamento de questões sensíveis como o racismo. Ao considerar as trajetórias de quatro intelectuais pioneiros nas temáticas do Atlântico negro - C. L. R. James, Eric Williams, Carter Woodson e W.E.B. Du Bois - pretende-se identificar problemas e temas relevantes para o ensino nessa área de estudos.
\end{abstract}

Palavras-chaves: Atlântico negro. Saberes acadêmicos. Ensino de História.

\section{Black Atlantic: academic narratives and teaching issues on the History of Americas}

Abstract: the article addresses academic knowledges on the History of the Americas to highlight its extent to enroll in a teacher training committed to tackling sensitive issues such as racism. By considering the trajectories of four intellectual pioneers of the Black Atlantic studies - C.L.R. James, Eric Williams, Carter Woodson and W.E.B. Du Bois - the article aims to identify relevant issues and themes for this area of studies.

Keywords: Black Atlantic. Academic knowledge. Teaching History.

\section{A Lei $10.639 / 2003$ no contexto das Américas}

Em meio ao debate nacional e internacional sobre o enfrentamento do racismo, os movimentos negros e as políticas públicas de diferentes países das Américas apostaram historicamente na educação como estratégia de ação privilegiada. Uma vez que - Brasil conta hoje com legislação específica e diretrizes curriculares voltadas para a discussão das relações raciais na sala de aula, torna-se crescente o anseio de olhar em torno e avaliar o que se passa em outras áreas americanas. Dispondo de um conjunto de informações sobre o papel da educação na agenda política de redução das desigualdades raciais, já é possível apontar algumas conexões que aproximam distintos contextos nas duas últimas décadas.

Alguns marcos gerais do impacto dessa agenda nas Américas seguiram-se à III Conferência Mundial de Combate ao Racismo, Discriminação Racial, Xenofobia e Into-

\footnotetext{
* Professora do Departamento de História da Universidade Federal Fluminense (UFF). Agradeço aos colegas do Grupo de Estudo e Pesquisa Cultura Negra no Atlântico (CULTNA/ UFF) pelas reflexões e oportunidades de aprofundar discussões sobre esta temática e aos pareceristas da revista Fronteiras \& Debates pelas considerações e sugestões. E-mail: ufflarissa@gmail.com
} 
lerância Correlata, realizada na África do Sul, em 2001. Entre eles, destacou-se a criação, em 2005, de uma Relatoria Especial sobre os direitos das pessoas Afrodescendentes e Discriminação racial, como parte da Comissão Interamericana de Direitos Humanos. No mesmo ano, a Organização dos Estados Americanos constituiu um grupo de trabalho para elaborar o projeto de uma "Convenção Interamericana contra o Racismo e Toda Forma de Discriminação e Intolerância". Na versão discutida em 2012, durante a fase de negociação do projeto, a elaboração e implementação de conteúdos e materiais pedagógicos que combatam preconceitos foi destacada como prioridade para as áreas americanas. Muitas dessas discussões, ao lado de outras ações de militância contra o racismo, contribuíram para que a ONU propusesse a instauração da Década Internacional de Afrodescendentes a partir de 2015, referencial expressivo nas políticas de combate à discriminação e na discussão sobre dever de memória, justiça reparativa e ações afirmativas em escala internacional (Guimarães, 2006; Heymann, 2007; Scott, 2014).

No Brasil, a década de 2000 testemunhou avanços mais intensos na legislação e na formulação de diretrizes nacionais para a reeducação das relações étnico-raciais. Observa-se, neste mesmo período, uma série de iniciativas comparáveis em outras áreas do continente americano. Um breve olhar para as políticas públicas de educação nos Estados Unidos, na América do Sul e no Caribe aponta para as décadas de 1990 e 2000 como pontos de mutação para legislações, reformas curriculares e ações dedicadas a enfrentar o racismo a partir das salas de aula. Nos Estados Unidos, o Título 34, Parte 100 do Code of Federal Regulations, foi adotado em 13 de dezembro de 2000 com o propósito de tornar efetivas as garantias do título VI da Lei de Direitos Civis, de 1964. Tal lei previa a não discriminação com base em raça, cor ou nacionalidade nos programas financiados por verbas do Departamento de Educação (Estados Unidos, 2000). É inevitável a sensação do longo tempo de lutas decorrido até a garantia federal de um direito básico. Mas nos resta voltar a atenção para os combates políticos na promoção de uma agenda educativa mais plural e atenta aos desafios de uma nação com passado escravista e tensões raciais profundas no presente.

Os parâmetros nacionais para o estudo de História (History Standards) testemunham parte significativa dessas tensões nos Estados Unidos. Foram elaborados sob a direção do Centro Nacional para História nas Escolas (National Center for History in 
the Schools), sediado na Universidade da California, UCLA. Realizados com financiamento público do Departamento de Educação e do National Endowment for the Humanities, no contexto da reforma da educação básica iniciada na gestão de Bill Clinton, os parâmetros vieram a público pela primeira vez em 1994. Sob a coordenação do historiador Gary B. Nash (pesquisador da história da escravidão e do multiculturalismo na formação da nação norte-americana) e da educadora Charlotte Crabtree (especialista na temática do currículo no ensino básico), professores, comunidades escolares, associações históricas, universidades e diversas organizações civis envolveram-se na elaboração dos parâmetros. Considerando a tradição local nas políticas de ensino nos Estados Unidos, o texto não pretendia ser um currículo, mas antes uma proposição ampla para ser adotada seletiva e voluntariamente nas escolas públicas do país.

Na sessão relativa à História dos Estados Unidos, distribuída em 10 fases, do século XVII ao presente, figuraram os conteúdos sobre História da África, da escravidão, da resistência dos escravos, do racismo, da luta por direitos civis, entre outras temáticas afins. Para o último ano da educação básica, os parâmetros propuseram que os alunos norte-americanos discutissem o fim da política de segregação racial nas escolas (legalmente presente em vários estados do país até a década de 1950), bem como avaliassem as políticas de ação afirmativa no país. A controvérsia e o amplo debate gerados pela publicação destes parâmetros, particularmente entre 1994 e 1996, explicitaram as disputas sobre os usos do passado e sobre o tema das identidades nas salas de aula. Considerar que nem todos os atores históricos têm a mesma cor, gênero ou classe e incluir grupos antes largamente ignorados na narrativa nacional era (e permanece sendo) um desafio na relação entre saberes acadêmicos, sociedade civil e saberes escolares (Nash et al., 2000; Avila, 2015).

Na Colômbia, país com $10 \%$ de população afrodescendente, de acordo com o censo de 2005 , e $26 \%$, segundo fontes alternativas, a Lei 70 , de 1993, é considerada o instrumento legislativo central em matéria de promoção da igualdade racial. 0 âmbito da etnoeducação é destacado como um dos resultados mais positivos da referida lei, ao lado das ações voltadas à legitimação de propriedades coletivas para as comunidades afro-colombianas tradicionais (Mallo e Rodríguez, 2012). A Universidad del Pacifico tem sido reconhecida como centro irradiador desta perspectiva através da criação da Cátedra de Estudos Afro-colombianos, resultante do decreto 1.122 de 1998, com im- 
pacto nos currículos nacionais. Na Costa Rica, país com $2 \%$ de população afrodescendente, o vigor da legislação traduziu-se no Decreto 32.338 , de abril de 2005 , que criou a Comissão Nacional Afro-costarriquenha, estabelecendo mudanças curriculares e a proposição de novos materiais didáticos a fim de integrar a história dos negros ao processo educativo nacional (Mallo e Rodríguez, 2012).

Para tomar um exemplo do Caribe, este espaço tão diverso, por um lado, e, por outro, majoritariamente negro, pode-se considerar aqui o caso de Barbados, independente da Inglaterra desde 1966 e hoje parte da Comunidade Britânica. Com 18 a 20\% do orçamento anual do país dedicados à educação, os planos nacionais de educação e cultura, particularmente na década de 2000, ressaltaram a urgente necessidade de rever a narrativa eurocêntrica da nacionalidade na região, causadora da "sensação de impotência e falta de confiança da população caribenha em si mesma", segundo avaliações de instituições nacionais (Barbados, 2010).

Como professora de História das Américas em uma universidade pública, crescentemente envolvida com turmas dos cursos diurnos e noturnos das disciplinas do ciclo básico, comecei a me indagar sobre a experiência de lecionar em um campus cada vez mais plural sob o ponto de vista étnico-racial (Passos, 2015). Venho me perguntando especialmente sobre a percepção dos alunos em relação à Lei 10.639, de 9 de janeiro de 2003, que instituiu a obrigatoriedade do ensino de História da África e da Cultura Afro-brasileira (Pereira e Monteiro, 2013; Abreu e Mattos, 2008). Considerando especialmente o ensino da História das Américas - particularmente voltado para as dimensões comparativas e atlânticas de temas como história da escravidão, história indígena, mestiçagem, era das abolições, relações raciais, fronteiras e identidades nacionais em construção -, desejava saber se meus alunos percebiam a disciplina como um espaço para refletir sobre educação e relações étnico-raciais.

A aula de história, na escola e na universidade, pode ser um dos locais privilegiados no difícil processo de encarar a memória do tráfico, da escravidão e da experiência do racismo. A abordagem dos temas sensíveis em sala de aula é uma das condições para que a história ensinada seja relevante, especialmente quando conjugada a uma criteriosa seleção das fontes e a um preparo que auxilie professores e alunos na abordagem de acontecimentos traumáticos do passado, bem como da relação que despertam com o presente e o futuro. A maneira como estes temas afetam os estudantes 
exige dos professores uma formação que possibilite conduzir a reflexão, como ressalta Verena Alberti, para além do horror e da denúncia, sem deixar de reconhecer a relevância de ambos (Alberti, 2011).

Como apontou Ana Maria Monteiro (2007), o conhecimento histórico acadêmico permanece como a referência daquilo que é dito na escola, embora as demandas envolvidas e os contextos em que se desenvolvem os saberes escolares e a produção acadêmica sejam distintos. Penso que o diálogo entre estes campos, no Brasil, deve parte de seu êxito recente à Lei 10.639/2003 e às inovações curriculares que a ela se seguiram. A fecundidade das discussões em torno do tema nas disciplinas universitárias, nos coletivos de estudantes, nos projetos de extensão, nos programas de iniciação à docência no ensino básico e em inúmeras iniciativas de história pública testemunha a vinculação entre lei e práticas educativas renovadas. Por esta razão, os desafios e responsabilidades das universidades na formação docente voltada para a reeducação das relações raciais são amplos. Exigem, portanto, atenção ao debate sobre a educação histórica através dos diálogos entre os meios acadêmicos e os outros espaços de formação e elaboração de narrativas históricas (Albieri, 2011).

Neste artigo, gostaria de propor um percurso em torno de alguns saberes "acadêmicos" de História da Américas, para ressaltar em que medida se inscrevem em uma formação docente comprometida com o enfrentamento de questões sensíveis como o racismo. Penso que a vocação atlântica desta disciplina, ao lado da notável militância política de muitos dos "pioneiros do Atlântico Negro", constituem temas relevantes para o diálogo entre saberes e experiências na formação docente. Ao identificar aspectos das obras de quatro intelectuais negros - C. L. R. James, Eric Williams, Carter Woodson e W.E.B. Du Bois -, pretende-se privilegiar narrativas que entrecruzam as análises históricas aos conflitos raciais do Atlântico Negro, visando identificar problemas e temas relevantes para a formação docente nesta área.

\section{O Atlântico negro nas narrativas acadêmicas}

O mundo Atlântico foi profundamente marcado pela conjunção entre escravidão, tráfico e economia exportadora em larga escala. Entre 1492 e 1820, conforme apontam Laurent Dubois e Julius Scott (2010), cerca de dois terços das pessoas que 
cruzaram o Atlântico em direção às Américas eram africanos. A maior parte destes homens e mulheres escravizados trabalharam em áreas rurais, produzindo a base para a expansão e consolidação de sociedades atlânticas entre os séculos XVI e XIX. Nas últimas décadas, historiadores e antropólogos escreveram inúmeros trabalhos sobre as experiências diárias, visões de mundo, esperanças e formas de resistência que moviam o cotidiano de africanos, crioulos e mestiços neste vasto espaço que veio a ser chamado, mais recentemente, de Atlântico Negro (Gilroy, 2001). Muito antes que essa expressão se tornasse usual nos meios acadêmicos, na década de 1990, seu significado mais amplo estava dado: era uma forma de compreender e escrever a História que tornava os negros, escravizados ou livres, atores centrais da cena atlântica, ao lado de indígenas, europeus e outros sujeitos históricos deste mundo vasto e conectado. Os laços forçados do tráfico, do cativeiro e da violência das sociedades escravistas demonstravam o caráter profundamente desigual das conexões tecidas naquele contexto.

Um dos pioneiros da escrita sobre o Atlântico Negro foi o historiador Cyril L. R. James (1901-1989), nascido em Trinidad, então ainda colônia inglesa no Caribe, filho de pai professor e mãe letrada. James iniciou a vida profissional ensinando no Queen's Royal College, em sua cidade natal, até que se mudou em 1932 para a Inglaterra. Lá, a orientação marxista de seu trabalho consolidou-se ao lado da militância política na abordagem das questões do colonialismo e da diáspora africana. O trabalho mais notável de James foi certamente Os Jacobinos Negro (James, 2000), originalmente publicado em 1938. O livro, ao contar a história da Revolução Haitiana, colocava o protesto negro no centro do debate sobre o abolicionismo no fim do século XVIII. A Revolução que daria origem ao Haiti, o primeiro estado negro e livre das Américas, ingressava, com a obra de James, nas narrativas sobre a era revolucionária que mudou a face do mundo atlântico a partir da independência dos Estados Unidos (Armitage, 2004; Gomes, 2010; Morelli e Gómez, 2012; Tomich, 2004; Trouillot, 1995).

Contudo, o trabalho monumental desse autor caribenho, desvinculado do ambiente acadêmico, não alcançaria reconhecimento imediato na formação de uma tradição historiográfica sobre os processos revolucionários atlânticos. É significativo notar que o livro referencial do historiador R. R. Palmer, A Era da Revolução Democrática, publicado entre 1959 e 1964, tenha analisado os enlaces e tensões entre Europa e 
América nos processos revolucionários das últimas décadas do século XVIII sem dedicar-se à revolta escrava de São Domingos. Entre as décadas de 1960 e 90 este panorama seria bastante modificado. A historiografia produzida nas Américas sobre a escravidão, os processos abolicionistas e a história das relações raciais foi profundamente impactada pelas lutas por direitos civis e pela reflexão atenta à agência dos sujeitos históricos populares. A história das revoluções democráticas traria à cena personagens negros como os líderes revolucionários Toussaint L'Ouverture e Jean Jacques Dessalines, assim como os protagonistas anônimos, através de suas histórias de resistência, experiências cotidianas, vitórias e derrotas (Genovese, 1979; Foner, 1988; Blackburn, 2002 e 2013; Geggus, 2010).

Com os Jacobinos Negros, na década de 1930, James vinculou de maneira inovadora os rumos da Revolução Francesa à Revolução dos escravos em São Domingos. Relacionando o contexto da França e do Caribe francês, demonstrou como os eventos nessas duas áreas afetaram e definiram os rumos do processo revolucionário que conduziu à abolição da escravidão e à formação do estado haitiano. Anos antes de publicar seu livro, James escreveu a peça teatral Toussaint L'Ouverture, levada aos palcos londrinos em 1936, com o ator Paul Robeson no papel-título. A escolha narrativa de James tem lições importantes para os dias atuais. Afinal, narrar uma trajetória de vida em meio à complexidade de um processo coletivo de lutas é uma estratégia significativa para a reflexão sobre o ensino de história das questões sensíveis.

A educação para as relações raciais no Brasil, institucionalizada pelas Diretrizes Curriculares Nacionais para a Educação das Relações Étnico-Raciais e para o Ensino de História e Cultura Afro-Brasileira e Africana, de $2004^{1}$, destaca a importância de estudar a ação concreta de homens e mulheres negros, do Brasil e de outros países. Recomenda-se especificamente, nas Diretrizes, o estudo da participação dos africanos e seus descendentes na diáspora. Não surpreende, ao observarmos os nomes ali relacionados, que Toussaint L'Ouverture lidere a lista, ao lado da africana Rainha Nzinga. Penso que este convite a olhar para as trajetórias de vida é rico em muitos sentidos e particularmente interessante pela possibilidade de evitar visões históricas simplifica-

\footnotetext{
${ }^{1}$ O texto completo das Diretrizes de 2004, uma das ações resultantes da Lei 10.639/2003, encontra-se disponível em: http://www.acaoeducativa.org.br/fdh/wp-content/uploads/2012/10/DCN-s-Educacaodas-Relacoes-Etnico-Raciais.pdf_. Acesso em 1/10/2015.
} 
doras e heroicas. É um convite, talvez, para apreender, através das trajetórias individuais, aquilo que relaciona o ensino de história às nossas vidas: os avanços e recuos, as possibilidades e incertezas, as versões e contradições em meio aos processos históricos.

A obra de C. L. R. James apontou, certamente, para novas possibilidades na investigação do protagonismo negro em meio às lutas políticas do Atlântico. Poucos anos depois, o também historiador Eric Williams (1911-1981), conterrâneo de James em Trinidad e Tobago, expandiria as fronteiras da reflexão sobre as relações entre capitalismo e escravidão no mundo moderno e contemporâneo. Williams, primogênito de 11 irmãos, teve uma infância modesta e marcada pela excelência nos estudos. Tanto que aos onze anos obteve uma bolsa para estudar no Queen's Royal College, na cidade de Porto de Espanha, "um dos raros canais de ascensão social via educação abertos à população negra pobre da colônia”². Um de seus tutores nesta instituição foi C. L. R. James, que se tornaria uma influência intelectual decisiva em sua vida e em seu trabalho. O notável desempenho acadêmico conduziria Williams à Inglaterra, em 1932, após receber uma bolsa para estudar em Oxford. Escolheu o curso de História e desde então circulou entre mundos marcados por visões bastante distintas e concorrentes: a "escola imperial" ${ }^{3}$, dominante em Oxford, e os movimentos anticolonais radicais de Londres, que reuniam militantes do Caribe britânico e da África.

Desafiando a interpretação então dominante na historiografia britânica, o livro de Williams, Capitalismo e Escravidão, publicado em 1944, colocava o humanitarismo em segundo plano na narrativa sobre o abolicionismo no século XIX. Reconhecia na campanha abolicionista e nos humanitaristas ingleses um dos maiores movimentos de propaganda de todos os tempos. Mas não enxergava ali a grande força mobilizadora para o fim do tráfico atlântico nas possessões inglesas, aprovado pelo Parlamento em 1807. Nem para a condenação final do escravismo na região, instituída em 1833.

Williams argumentava que o capitalismo se assentava na ordem colonial, no escravismo e na lógica dos monopólios. "As Índias Ocidentais tinham erguido Manchester no século XVIII" (Williams, 2012, p. 184), afirmava, mas a região deixara de ser fun-

\footnotetext{
${ }^{2}$ As informações e análises sobre a biografia do autor e a recepção de seu livro no Brasil foram retiradas do prefácio à edição brasileira do trabalho de Williams, assinado por Rafael de Bivar Marquese.

${ }^{3}$ De acordo com Marquese, 2012, a perspectiva de análise predominante nesta escola veiculava os fundamentos ideológicos que legitimavam o império britânico.
} 
damental para a sobrevivência e a vitalidade do Império no século XIX. Após 1783, setores econômicos importantes passaram a investir contra o monopólio e o sistema colonial. No século XIX, o sistema escravista já não seria tão rentável e a nova ordem industrial dependia da defesa do livre comércio, da construção da lógica do trabalho livre e, portanto, da superação do escravismo nos marcos do Império inglês.

Ao contrapor-se à narrativa humanitarista, Williams rompia a tradição historiográfica dominante na Inglaterra nas primeiras décadas do século $X X$, inclusive aquela produzida na Universidade de Oxford, onde ele havia realizado seu doutorado. A marca da adesão ao nacionalismo caribenho também se inscrevia nesse livro, que discutia as relações entre colonialismo e Império na esteira da Segunda Guerra Mundial. Capitalismo e escravidão tornava-se, portanto, uma das fundações intelectuais do Caribe autônomo. Seu autor, aliás, não demoraria a aderir à luta anticolonial, tornando-se primeiro ministro de Trinidad e Tobago em 1962, após a independência do país (Marquese, 2012).

Assim como James, Eric Williams lançou mão de um modelo de análise que conectava distintas partes do mundo Atlântico para explicar e compreender os processos históricos que conduziram à queda do escravismo entre o final do século XVIII e o século XIX. Muitos críticos apontaram a vulnerabilidade dos argumentos deste autor, ressaltando o excessivo peso dos interesses materiais em sua explicação do abolicionismo britânico. Alguns historiadores debateram a tese de Williams questionando a noção da drástica redução de importância da economia escravista no período analisado (Eltis, 1987). Outros argumentaram que o abolicionismo nas áreas britânicas tornou-se irresistível pelo caráter popular da mobilização antiescravista (Drescher, 2009). Ao mesmo tempo, o legado deste trabalho seminal comprovou (e ainda comprova) sua força extraordinária, estimulando a ampliação dos debates e novas interpretações ${ }^{4}$.

Williams afirmava que não pretendeu fazer um estudo sobre a instituição escravista, propriamente. Tratava-se, antes, de uma investigação sobre a contribuição da escravidão para o desenvolvimento do capitalismo britânico. Ao encerrar a análise, observou que os escravos, a "força social mais poderosa e dinâmica nas colônias" (Williams, 2012, p. 274), haviam sido ignorados pela maioria dos que estudavam a temáti-

\footnotetext{
${ }^{4}$ Um panorama amplo de debates recentes em torno da obra de Eric Williams pode ser encontrado em Shields, 2015.
} 
ca. Ao elencar os autores que "vinham despertando para as distorções resultantes deste fato" (Williams, 2012, 269), citou seu conterrâneo e interlocutor por muitos anos, C.L.R. James. E também Herbert Aptheker (1915-2003), historiador marxista norteamericano, especialista na rebeldia e resistência escrava, além do antropólogo Melville Herskovitz (1895-1963), especialista precursor nos estudos africanos e afro-americanos no campo da antropologia nos Estados Unidos.

É interessante observar que Williams ensinava Ciências Sociais e Política na Universidade de Howard, em Washington, quando publicou Capitalismo e Escravidão. Lecionou entre 1939 e 1948 nesta universidade, fundada logo após a Guerra Civil, dedicada à educação dos afro-americanos e ainda hoje majoritariamente frequentada por alunos e alunas negros. O diálogo acadêmico estabelecido em Capitalismo e Escravidão não buscou uma conexão direta com a Black History produzida por historiadores negros dos Estados Unidos. Mas a trajetória acadêmica do autor relacionava-se de perto com o ambiente político e intelectual da Universidade de Howard nos anos da Segunda Guerra Mundial. A discussão antirracista e anti-imperialista em escala global encontrava ali um terreno fértil. Williams era colega do sociólogo E. Franklin Frazier (1894-1962), do filósofo e crítico literário Alain Locke (1886-1954) e aproximou-se do historiador Carter Woodson, que havia passado por Howard anos antes. Editor comprometido com o internacionalismo negro, Woodson publicou trabalhos de Williams, permitindo-nos tecer a rede de contatos que configurou o ambiente de militância, ensino e produção historiográfica destes pioneiros do Atlântico Negro (Gaspar, 2003). Tais conexões também nos fazem recordar que o trabalho destes intelectuais se realizava em meio ao ambiente norte-americano do racismo institucionalizado, das práticas de segregação racial e da cidadania restritiva imposta aos negros naquele contexto.

Carter G. Woodson (1875-1950) é frequentemente apontado como o "Pai da História Negra" nos Estados Unidos, denominação que remete seguramente, mas não apenas, aos esforços para integrar a produção acadêmica ao âmbito do ensino da História nas escolas do país. Woodson nasceu em New Canton, Virginia, em uma família extensa, filho de pais ex-escravos que não puderam oferecer uma educação formal aos filhos. Já empregados e desejosos de oportunidades para se educar, ele e seu irmão, Robert Henry, investiram na auto-instrução das matérias básicas e só chegaram aos bancos escolares em idade mais avançada. Em 1895, aos vinte anos de idade, Wood- 
son começou a frequentar a Douglass High School, na qual se formou no ano de 1897, iniciando imediatamente depois uma carreira como professor, diretor e supervisor de escolas. A continuidade dos estudos acadêmicos levou-o à Universidade de Harvard, onde concluiu seu doutoramento em História, em 1912.

O ativo trabalho na institucionalização do campo de estudos que viria a ser consagrado como Black History teve início logo após a sua passagem por Harvard. Ao longo das décadas seguintes, Carter Woodson liderou a organização de uma série de inciativas voltadas para o desenvolvimento de redes de pesquisa, publicação e divulgação da história dos negros e das relações raciais. Foi um dos principais fundadores da "Associação para o estudo da vida e da história dos negros", criada nos Estados Unidos em 1915, e primeiro editor do Journal of Negro History, fundado em 1916. Em 1920 fundou a Associated Publishers, uma editora voltada para a publicação de pesquisas, documentos e trabalhos diversos sobre a temática das relações raciais. Pouco tempo depois, em 1926, Woodson liderou a criação da "Semana da História do Negro" em âmbito nacional, celebrada anualmente (atualmente é comemorada como o mês da História $\mathrm{Negra}^{5}$, em fevereiro). Contribuiu também para ampliar o compromisso de seu grupo com o ensino desta temática nas escolas primárias e secundárias através da publicação de um novo periódico, o Negro History Bulletin, iniciado em 1937.

Dirigido a professores e alunos, as edições deste boletim eram relativamente curtas, variando entre 15 e 20 páginas na década de sua fundação. Além dos artigos, cada número trazia uma seção de indicação de livros, a chamada página das crianças (com atividades lúdicas sobre os temas abordados) e uma parte dedicada a perguntas e respostas relativas aos assuntos discutidos no número anterior. Artigos como "Por que estudar África?", "Negros na Guatemala", "Brasil: a maior nação negra” ou "O rei negro do Haiti", entre outros títulos, enchiam as páginas do periódico, convidando os leitores norte-americanos a refletir sobre questões que ultrapassavam as fronteiras nacionais. $^{6}$

História acadêmica, historiadores amadores, história escolar... A variedade nas formas de escrita da história e nas posições políticas assumidas pelos historiadores

\footnotetext{
${ }^{5}$ Para uma discussão sobre a história negra como história americana, ver Dorsey, 2007.

${ }^{6}$ Exemplos retirados de Negro History Bulletin, volume 4, 1940-1. As edições variavam, podendo-se notar que em 1940 uma edição alcançou 3 números, e, em 1941, 6 números publicados. O periódico continua a ser publicado, hoje com o título Black History Bulletin.
} 
negros no período aqui analisado exige atenção. A disputa entre Booker T. Washington (1858-1915) e W. E. B. Du Bois (1868-1963) traduz algo das tensões notáveis, ainda que aparentemente diluídas, quando lançamos mão de rótulos como Black History. Booker Washington (1909), ex-escravo, educador, intelectual e um dos líderes comunitários negros mais expressivos de sua geração, defendia linhas de ação mais conciliatórias, pragmáticas e moderadas para a ascensão dos negros norte-americanos. Já Du Bois, historiador e ativista negro, avaliava o silêncio em relação aos direitos políticos e civis como um legado desastroso de Booker Washington e seus partidários. Para Du Bois, os negros deveriam "insistir sempre, no inverno e no verão, em que votar é necessário para o adulto moderno, que preconceito de cor é barbarismo, e que meninos negros precisam tanto de educação quanto os meninos brancos", em palavras do início do século XX (Du Bois, 1999, p. 111) ${ }^{7}$. Se as experiências de mulheres e homens negros jamais conformaram um bloco de ação e pensamento unívocos, o mesmo se pode dizer sobre a História Negra como campo intelectual em construção entre o fim do século XIX e as primeiras décadas do século XX. Era tributária de tradições distintas e projetos sociais concorrentes, certamente. Mas necessariamente escrita, nos Estados Unidos, sob o pano de fundo das leis de segregação racial, dos linchamentos e de uma cidadania bastante instável.

Du Bois nasceu em 1868 em Great Barrington, no estado de Massachusetts, fiIho de uma família de negros e mestiços livres. O pai, com quem conviveu pouco, era barbeiro e trabalhador itinerante e a mãe, empregada no serviço doméstico. $\mathrm{O}$ ano de seu nascimento é um marco para as comunidades negras recém saídas da Guerra Civil e da abolição, pois foi em 1868 que se ratificou a XIV Emenda à Constituição dos Estados Unidos, estendendo aos libertos o direito de cidadania plena. Após receber uma educação clássica ${ }^{8}$, Du Bois formou-se no curso secundário de sua cidade natal. Com a experiência de ser o único estudante negro em uma turma de treze alunos, na escola secundária racialmente integrada de Great Barrington, este jovem ingressaria na Fisk University, em Nashville, Tennessee.

Assim, mudava-se da Massachusetts natal para o Sul, em 1885, apenas alguns

\footnotetext{
${ }^{7}$ Sobre as tradições distintas na formação da História Negra como campo de produção intelectual, ver Reddick, 1937.

${ }^{8}$ Para uma análise das relações entre modernidade, racialização e formação de uma elite negra nos Estados Unidos no período pós-abolição, ver Nascimento, 2015.
} 
anos depois da criação da primeira lei de segregação dos negros em transportes públicos, aprovada precisamente naquele estado do Tennessee. Em Fisk, uma das melhores universidades sulistas fundadas após o término da Guerra Civil para a população de negros livres, Du Bois teve a chance de prosseguir seus estudos clássicos, dedicando-se às disciplinas de alemão, grego, latim, literatura clássica, filosofia, ética, química e física. Lá recebeu também a decisiva influência de professores herdeiros da tradição abolicionista nortista, entrou em contato com as particularidades do racismo sulista, com a riqueza da cultura musical afro-americana (Abreu e Viana, 2011) e viveu a experiência de ser professor em comunidades negras pobres do Sul rural. ${ }^{9}$

A revelação explícita dos efeitos da opressão racial, do preconceito e da discriminação nas comunidades negras foi a marca da escrita e da atuação política de Du Bois. Presente em seu admirável livro de mocidade, publicado em 1903, a metáfora do "véu" separando a América branca da América negra era recorrente na escrita desse historiador negro. Em suas contundentes palavras, "o problema do século XX é o problema da barreira racial" (Du Bois, 1999, p. 49) e "ser um problema é uma experiência estranha" (Du Bois, 1999, p. 52).

Em 1935, quarenta anos após haver concluído seu doutorado em Harvard, Du Bois publicou aquele que talvez seja o trabalho mais monumental de uma longa vida de atividade política e intelectual. Tratava-se de um estudo sobre o período conhecido como "Reconstrução" da democracia americana (1867-1876), marcado por uma série de ações nos estados e na União voltadas para a garantia dos direitos celebrados pela Emenda XIV, na esteira da Guerra Civil. O livro, intitulado Black Reconstruction in America (Du Bois, 1992), encerrava-se com um capítulo dedicado ao ensino da História, intitulado "The propaganda of history". De acordo com Du Bois, a Reconstrução era ensinada nas aulas de História das escolas norte-americanas a partir de três visões predominantes: todos os negros eram ignorantes; todos os negros eram desonestos, extravagantes e perigosos; e os negros eram os responsáveis pelo mau governo durante o período da Reconstrução. A visão negativa sobre o período pós-emancipação veiculada nos manuais didáticos do século XX era, para o autor, tributária de uma corren-

\footnotetext{
${ }^{9}$ Para uma detalhada apresentação sobre a vida de W.E.B. Du Bois, ver a introdução de Heloisa Toller Gomes, que também traduziu para o português e preparou a cronologia histórica e as notas da obra As almas da Gente Negra, 1999.
} 
te histórica influente desde o período pós-Guerra Civil, liderada pelos trabalhos de John Burgess e William A. Dunning, professores de Ciência Política e História, respectivamente, na Universidade de Columbia ${ }^{10}$. Tal visão histórica apresentava simpatia pelos ideais de supremacia branca, ao considerar negros e libertos como "incivilizados", "bárbaros" e, portanto, supostamente inaptos para a vida política e para o exercício do governo.

Du Bois iniciou sua pesquisa sobre a Reconstrução mais de vinte e cinco anos antes de publicá-la, quando era professor das áreas de História e Economia da Universidade de Atlanta. Escrevendo contra os argumentos de supremacia branca, ressaltava o papel do voto negro na restauração do Sul à União, no estabelecimento de uma nova democracia - para brancos e negros -, e na instituição de escolas públicas. A escrita de Du Bois registrava o papel do negro na preservação da União e da democracia norteamericanas, ressaltando a importância da radical experiência vivida entre 1865 e 1876. Reafirmava que os negros, predominantemente por iniciativa própria, haviam ampliado as chances de educar-se, e este teria sido "um dos mais extraordinários desenvolvimentos dos dias modernos" (Du Bois, 1992, p. 589) potencializando as condições de aplicar e desenvolver o poder político alcançado no período da Reconstrução.

Entretanto, os limites impostos à cidadania negra no pós-abolição eram também sublinhados por Du Bois, para quem a guerra civil, no Sul, jamais acabara. A guerra civil (com letras minúsculas, no original) a qual ele se referia representava o esforço de submeter o trabalhador negro à condição de "exploração ilimitada" (Du Bois, 1992). Para Du Bois, o salário do trabalhador negro foi, então, reduzido ao nível da mera subsistência por força das taxações, da peonagem e de diversas formas de discriminação racial, constituindo "um aberto desafio à letra da lei", característica crucial do Sul naquele contexto, segundo o autor.

Nos anos de 1950 e 1960, quando a interpretação que atribuía à Reconstrução um papel trágico na história da nação já era contestada em parte expressiva da historiografia norte-americana, o papel da lei nos estados sulistas retornaria ao centro do debate. O curso dos acontecimentos que desencadearam uma revolução nas relações raciais, com o crescimento das lutas pelos direitos civis e políticos da população negra,

\footnotetext{
10 John W. Burgess escreveu Reconstruction and the Constitution, 1866-1876, publicado em 1902, e William A. Dunning é autor de Reconstruction, Political and economic, 1865-1877, publicado em 1907.
} 
já indicava um renovado debate historiográfico sobre o período pós-emancipação. Nesse contexto, a publicação de The Strange carreer of Jim Crow, em 1955, marcou época. Martin Luther King considerava este trabalho, escrito pelo historiador sulista C. Vann Woodward, como a "bíblia histórica" do movimento pelos direitos civis nos Estados Unidos. O trabalho de Woodward foi originalmente publicado um ano depois de a Corte Suprema julgar o caso Brown vs. Conselho de Educação, ${ }^{11}$ decidindo por unanimidade, após longos debates, que a segregação de alunos em escolas públicas do país era inconstitucional. A história das relações raciais e a história da vida escolar, em muitos sentidos, entrelaçou-se nas margens do Atlântico negro, tornando importante, sempre, a renovação dos debates sobre a História ensinada nestes espaços.

\section{Considerações finais}

A dimensão atlântica das lutas contra a escravidão e o racismo, ressaltada pelos diferentes intelectuais aqui privilegiados, iluminou algumas perspectivas em particular: o protagonismo negro na era das revoluções; a relação entre escravidão, capitalismo e abolicionismos; o internacionalismo negro na escrita da história escolar e a questão racial no período pós-abolição. Se nos ajudam a refletir sobre violência racial no cotidiano e na sala de aula é porque, entre outras razões, estes autores pontuam a pluralidade de experiências e identidades que o Atlântico negro permite observar.

Como afirma o sociólogo britânico Paul Gilroy, um dos desafios para os investigadores contemporâneos interessados na questão das identidades é a consideração de que cultura negra não é uma essência: "a história do Atlântico negro fornece um vasto acervo de lições quanto à instabilidade e à mutação de identidades que estão sempre inacabadas, sempre sendo refeitas" (Gilroy, 2001, p. 30). Para Gilroy, uma inevitável hibridez, instabilidade e mistura de ideias caracterizaram os contatos e interações en-

\footnotetext{
${ }^{11}$ Ver texto original da decisão judicial em Syrett,1980. A decisão da Suprema Corte em 1954, determinando o fim da prática das escolas separadas, foi contestada por diversos estados sulistas e constituiu um dos marcos da precipitação dos protestos de comunidades negras na região. A decisão, de 1954, anulava a doutrina "separados, mas iguais" (Separate, but equal, originalmente), proferida pela Suprema Corte em 1896. De acordo com a decisão de 1896, haveria igualdade quando negros e brancos eram providos de instalações substancialmente iguais, ainda que fisicamente separadas. Criavam-se, assim, os precedentes legais para práticas discriminatórias de manutenção de escolas separadas para os negros, de locais separados nos transportes, nos restaurantes e em outros serviços públicos.
} 
tre diferentes tradições socioculturais neste espaço. Que uma formação comprometida com o ensino de História e o enfrentamento da violência racial nas salas de aula esteja atenta a estes aspectos é o que se deseja. Sem desconhecer, por certo, que esta é apenas uma de muitas tarefas em meio ao desafio mais amplo da reeducação para as relações étnico raciais nas salas de aula de escolas e universidades.

A História das Américas integra os currículos brasileiros, com intensidade e ênfases variáveis, desde o século XIX. Neste período, foram as discussões historiográficas, políticas, identitárias e pedagógicas de cada tempo que informaram as relações entre currículos, conteúdos e práticas docentes. No momento em que o Brasil debate a constituição de uma Base Nacional Comum Curricular, projeto lançado em 2015, a discussão apontada pelos pioneiros do Atlântico negro parece mais do que oportuna. Afinal, contribuíram para evidenciar novas maneiras de olhar para as histórias de homens e mulheres que, até então, não integravam de forma significativa as narrativas históricas sobre as Américas. Para investir em uma visão de futuro que valorize tais histórias, não nos deve escapar a tarefa de olhar para esse passado considerando as estratégias de uma formação docente fortemente comprometida com a luta contra o racismo.

\section{Referências Bibliográficas}

ABREU, M.; MATTOS, H. 2008. Em torno das Diretrizes curriculares nacionais para a educação das relações étnico-raciais e para o ensino de história e cultura afrobrasileira e africana: uma conversa com historiadores. Estudos Históricos (Rio de Janeiro), v. 21, p. 5-20.

ABREU, M.; VIANA, L. 2011. Lutas políticas, relações raciais e afirmações culturais no pós-abolição: Os Estados Unidos em foco. In: AZEVEDO, C.; RAMINELLI, R. (org.). História das Américas: novas perspectivas. Rio de Janeiro, FGV Editora, p. 161-190.

ALBERTI, V. 2011. Oral history interviews as historical sources in the classroom. Words \& Silences, v. 6, pp. 29-36.

ALBIERI, S. 2011. História Pública e consciência histórica. In: ALMEIDA, J. R. de; ROVAI, M. (org.). Introdução à História Pública. São Paulo, Letra e Voz, pp. 19-28.

ARMITAGE, D. 2004. "Tres conceptos de historia atlántica". Revista de Occidente, n. 281, pp. 7-28; 
ÁVILA, A. 2015. A quem pertence o passado norte-americano? A controvérsia sobre os National History Standards nos Estados Unidos. Anos 90, Porto Alegre, v. 22, n. 41, pp. 29-53.

BARBADOS. 2010. National Cultural Policy for Barbados. Barbados, The Ministry of Community Development and Culture.

BLACKBURN, R. 2002. A queda do escravismo colonial. Rio de Janeiro, Record.

BLACKBURN, R. 2013. American Crucible: Slavery, Emancipation and Human Rights. London, New York, Verso.

DORSEY, A. 2007. Black History is American History: teaching African American History in the Twentieth First Century, The Journal of American History, vol. 93, n. 4, pp. 11711177.

DRESCHER, S. 2009. Abolition: a History of Slavery and Antislavery. New York, Cambridge University Press, 2009.

DU BOIS, W.E.B. 1992. Black Reconstruction in America, 1860-1880. New York, The Free Press.

DU BOIS, W.E.B. 1999. As almas da Gente Negra. Rio de Janeiro, Lacerda Editores.

DUBOIS, L.; SCOTT, J. S. (Editors). 2010. Origins of the Black Atlantic. New York \& London, Routledge.

ESTADOS UNIDOS. 2000. Code of Federal Regulations, Lei 34, Parte 100, de 13 de dezembro de 2000. Disponível em: http://www2.ed.gov/policy/rights/reg/ocr/edlite34cfr100.html Acesso em 10/09/2015.

ELTIS, D. 1987. Economic Growth and the ending of Transatlantic Slave Trade. New York, Oxford University Press.

FONER, E. 1988. Nada além da liberdade. Rio de Janeiro, Paz e Terra.

GABRIEL, C. 2012. Teoria da História, Didática da História e narrativa: diálogos com Paul Ricoeur". Revista Brasileira de História (Online), v. 32, pp. 187-210.

GEGGUS, D. 2010. The Caribbean in the age of Revolution. In: ARMITAGE, D.; SUBRAHMANYAM, S. The age of Revolutions in global context, 1760-1840. New York, Palgrave Macmillan.

GENOVESE, E. 1979. From rebellion to Revolution: afro-American slave revolt in the making of modern world. Baton Rouge and London, Louisiana State University Press, 1979. 
GILROY, P. 2001. O Atlântico Negro: modernidade e dupla consciência. Rio de Janeiro/São Paulo, UCAM/Editora 34.

GOMES, F. 2010. "Ideas, significados y Cultura politica en la Historia Atlántica de la esclavitud en las Americas". Historia y Politica: ideas, procesos y movimientos sociales, v. 23, pp. 299-315.

GUIMARÃES, A. 2006. Depois da democracia racial. Tempo Social, Revista de Sociologia da USP, v. 18, n.2, pp. 269-287.

HEYMANN, L. 2007. O devoir de mémoire na França contemporânea. In: GOMES, A. (org.). Direitos e cidadania: memória, política e cultura. Rio de Janeiro, Editora FGV, pp. 15-43.

HOLT, T. 2008. Du Bois, W. E. B. In: GATES JR., H.; HIGGINBOTHAM, E. African American National Biography. New York, Oxford University Press, 2008. Disponível em: http://hutchinscenter.fas.harvard.edu/dubois/about-w-e-b-du-bois Acesso em 18/10/2015.

JAMES, C.L.R. 2000. Os Jacobinos Negros: Toussaint L'Ouverture e a revolução de São Domingos. São Paulo, Boitempo Editorial.

MALLO, T.; RODRÍGUEZ, M. 2012. Los afrodescendientes frente a la educación: Panorama regional de América Latina. Serie Avances de Investigación, $n^{\circ} 75, \mathrm{CeALCl}$ - Fundación Carolina, Madrid.

MARQUESE, R. 2012. Capitalismo e Escravidão e a historiografia sobre a escravidão negra nas Américas, In: WILLIAMS, E. Capitalismo e Escravidão. São Paulo, Companhia das Letras.

MONTEIRO, A. M. 2007. Narrativas e Narradores no Ensino de História. In: MONTEIRO, A. M.; GASPARELlO, A.; MAGALHÃES, M. (org.). Ensino de História: sujeitos, saberes e práticas. Rio de Janeiro: Mauad X/Faperj, pp. 119-135.

MORELLI, F.; GÓMEZ, A. E. 2012. La nueva Historia Atlántica: un asunto de escalas, Nuevo Mundo Mundos Nuevos [Online], Bibliografias, Disponível em: http://nuevomundo.revues.org/2102 Acesso em 28/02/2017.

NATIONAL CENTER FOR HISTORY IN THE SCHOOLS. 1996. National Standards for History, Basic Edition, UCLA. Disponível em: http://www.nchs.ucla.edu/history-standards Acesso em 10/09/2015.

NASCIMENTO, G. 2015. Os perigos dos Negros Brancos: cultura mulata, classe e beleza 
eugênica no pós-emancipação (EUA, 1900-1920). Revista Brasileira de História (Online), v. 35 , pp. $155-176$.

NASH, G.; CRABTREE, C.; DUNN, R. 2000. History on Trial: Culture Wars and the Teaching of the Past. Vintage Books Edition.

PALMER, R. R. 1959/1964. The Age of the Democratic Revolution: A Political History of Europe and America, 1760-1800. Princeton University Press, volumes 1 e 2.

PASSOS, J. 2015. Relações raciais, cultura acadêmica e tensionamentos após ações afirmativas. Educação em Revista. Belo Horizonte, vol. 31, n. 02, pp. 155-182.

PEREIRA, A.; MONTEIRO, A. M. (org). 2013. Ensino de História e culturas afrobrasileiras e indígenas. Rio de Janeiro, Pallas.

PHILLIPS, C. 2001. C.L.R. James: The Most Noteworthy Caribbean Mind of the Twentieth Century, The Journal of Blacks in Higher Education, n. 33, pp. 118-120.

REDDICK, L. D. 1937. A New Interpretation for Negro History, The Journal of Negro History, vol. 22, n. 1, pp. 17-28.

SCOTT, D. 2014. On the Moral Justification of Reparations for New World Slavery. In: NICHOLS, R. and SINGH, J. (Editors), Freedom and Democracy in an Imperial Context: Dialogues with James Tully. New York, Routledge, pp. 100-20.

SHIELDS, T. 2015. The legacy of Eric Williams: Into the postcolonial moment. University Press of Mississippi.

SYRETT, Harold. 1980. Documentos históricos dos Estados Unidos. São Paulo, Cultrix. TOMICH, D. 2004. O Atlântico como espaço histórico, Estudos Afro-Asiáticos, 26 (2), pp. 221-240.

TROUILLOT, M. R. 1995. Silencing the Past: power and the production of history. Boston, Beacon Press.

WASHINGTON, B. T. 1909. The story of the negro: the rise of the race from slavery. New York, Association Press.

WILLIAMS, E. 2012. Capitalismo e Escravidão. São Paulo, Companhia das Letras.

Artigo recebido em 01 de março de 2017 e aprovado em 18 de junho de 2017. 